\title{
RoboSTEAM project the pilot phases
}

\author{
Miguel Á. Conde \\ University of León \\ mcong@unileon.es \\ Covadonga \\ González-Barrientos \\ I.E.S Eras de Renueva \\ covadongag@ieserasderenueva.org \\ José Gonçalves \\ Instituto Politécnico de Bragança \\ goncalves@ipb.pt
}

\author{
Camino Fernández-Llamas \\ University of León \\ cferll@unileon.es \\ Maria Ramos \\ Agrupamento de Escolas Emídio \\ Garcia \\ f331aepq@gmail.com \\ Daniela Reimann \\ Karlsruhe Institute of Technology \\ daniela.reimann@kit.edu \\ Ilkka Jormanainen \\ Karlsruhe Institute of Technology \\ ilkka.jormanainen@uef.fi
}

\author{
Francisco J. Rodríguez-Sedano \\ University of León \\ fjrods@unileon.es
Manuel Jesus
Colégio Internato dos Carvalhos manuel.jesus@cic.pt
Francisco José García-Peñalvo
University of Salamanca
fgarcia@usal.es

\begin{abstract}
Digital society demands very qualified professionals ready to this environment challenges. This makes necessary to foster the development of competences related to such context such as Computational Thinking or STEAM related skills. However, this is not an easy task, especially because integrating subjects that covers the necessary topics and competences. New active pedagogical approaches are required and this what RoboSTEAM project provides. The application of Challenge Based Learning and Physical Devices and Robotics facilitate the so named twenty first century skills. The project has been developed by several universities and schools and one of most critical parts was testing the methodology and tools, this was done into pilot phases that are described in the present work. The results show that there are important differences between partners socioeconomical context, but that the outcomes of the project are flexible enough to be applied successfully in any of them.
\end{abstract}

\section{CCS CONCEPTS}

- Applied computing $\rightarrow$ Education; • Computer systems organization $\rightarrow$ Embedded and cyber-physical systems; Robotics; • Social and professional topics $\rightarrow$ Professional topics; Computing education; Computational thinking; Professional topics; Computing education; K-12 education.

\section{KEYWORDS}

STEAM, Computational Thinking, Robotics, Physical Devices, Evaluation, Pilots

Permission to make digital or hard copies of all or part of this work for personal or classroom use is granted without fee provided that copies are not made or distributed for profit or commercial advantage and that copies bear this notice and the full citation on the first page. Copyrights for components of this work owned by others than the author(s) must be honored. Abstracting with credit is permitted. To copy otherwise, or republish, to post on servers or to redistribute to lists, requires prior specific permission and/or a fee. Request permissions from permissions@acm.org.

TEEM'21, October 26-29, 2021, Barcelona, Spain

(C) 2021 Copyright held by the owner/author(s). Publication rights licensed to ACM. ACM ISBN 978-1-4503-9066-8/21/10 .. \$15.00

https://doi.org/10.1145/3486011.3486417
ACM Reference Format:

Miguel Á. Conde, Camino Fernández-Llamas, Francisco J. RodríguezSedano, Covadonga González-Barrientos, Maria Ramos, Manuel Jesus, José Gonçalves, Daniela Reimann, Francisco José García-Peñalvo, and Ilkka Jormanainen. 2021. RoboSTEAM project the pilot phases. In Ninth International Conference on Technological Ecosystems for Enhancing Multiculturality (TEEM'21) (TEEM'21), October 26-29, 2021, Barcelona, Spain. ACM, New York, NY, USA, 7 pages. https://doi.org/10.1145/3486011.3486417

\section{INTRODUCTION}

Current society demands professionals adapted to the digital society. This means that they should have achieved what is known as 21st century skills and they should be flexible enough to deal with a changeable context. This makes especially necessary to facilitate the acquisition of such skills through the integration of STEAM related activities in the present educational pathways and to foster competences such as Computational Thinking [1-3]. Both tasks are hard, it is not enough to include some technology subjects in the educational plan, the development of these competences must be something included in all the subjects and the best way to facilitate this is using active methodologies and using engaging tools for the students $[1,4,5]$.

In this sense there are different projects and trends that promote the development of these competences and STEAM integration. Some aim to engage and facilitate teachers and policy makers materials and guides to develop new integrated STEAM approaches, such as ENQUIRE [6], Mind the Gap [7], PRIMAS [8], Scientix [9], KIKS [10]. Other are more focused on facilitate knowledge and content exchanging such as STELLA [11] or GRID [12] or CONTEXTEuroSTEAM [13]. Finally, some of them deal with STEAM perception among students such as YOSCIWEB [14], STEM Alliance [15], inGenious [16], RAISE [17] or W-STEM project [18, 19].

RoboSTEAM is a project that deals with these topics. It is an Erasmus+ Strategic Partnership project that involves 8 partners from 4 different countries ( 4 schools and 4 universities) with the aims 
to define a methodology and a set of tools that help learners to develop computational thinking by using/programming PD\&R in preuniversity education stages. The project will also improve teacher education, providing them with a framework for easy STEAM integration in different educational contexts, by providing guidelines for good practices and lessons learned adapted to those contexts. All these products will be tested in different countries and crossvalidated in different educational institutions [20]. This will be done through a set of pilots and by the exchange of students and teachers between the schools involved in the project.

In this paper we would like to present the two project pilot stages. They began on the M12 of the project and were scheduled to finish around M20 the problem was COVID-19 pandemic situation that causes a change in this initial plan. 2 will describe the pilots, their aims, the stakeholders involved, and the assessment tools applied. 3 presents the challenges addressed by each partner. 4 show some of the obtained results. Finally, some conclusions are posed in 5.

\section{THE PROJECT PILOTS}

This section describes RoboSTEAM pilot descriptions, for more information about them it is possible to review the project management handbook [21] or the reports for activities 3 [22] and 4 [23].

\subsection{Pilot Phase 1}

This stage was defined in the project proposal as activity 3 or A3: "it will launch the testing of both RoboSTEAM methodology and PD\&R testing kits. During this pilot the 5 secondary schools are involved with their students from 12 to 16 years old. The pilots consist of a first diagnostic phase, later challenges will be posed for small students' groups, and finally the results will be analyzed. During the diagnostic phase all students in the previous commented range of ages will fulfil a questionnaire about their perception about STEAM and how it is taught in their school. After this, 4 challenges will be posed to a class of secondary students. They will solve these problems and the results will be analyzed and compared with the students that do not participate in the challenge. Indicators to be used could include: the time employed, the grade obtained, the external people involved, the assessment of computational thinking and STEAM related competences acquisition by using the instruments and methods defined in O1, and students self-perception about the experiment" [21].

The activity was scheduled to be completed between project months 9 and 17 although this task was delayed because it requires for the results of previous activities completed during the first year and because COVID-19 [24, 26, 26-36]. In most of the cases this has meant to delay the end of the pilot stage or to have to complete it in smaller groups or virtually [37].

\subsection{Pilot Phase 2}

This stage is defined by the project proposal as activity 4 , it consists of: "A4 will launch a second testing stage. The secondary schools will be involved again. They should develop the same activities than in Pilot 1, and the same students' groups are involved in the challenges. In this case students can choose the instruments, methods and tools from other socioeconomic contexts present in
RoboSTEAM environment. The idea is analysing how PD\&R kits work in a different socioeconomical context. Later the results will be compared with students that do not participate in the challenges, and with the results obtained during Pilot1. The indicators to be used are the same of Pilot1" [21].

The pilot stage was scheduled between months 12 and 19 although, as in the previous case the pilot was delayed because the dependency with other project results, that were also delayed because of the late beginning of the project, and because of problems associated to the COVID-19 pandemic situation that arose on month 18 of the project. In this case the classes included in the pilots were discontinued, and the partners should look for ways to finish both this pilot phase and pilot phase 1 . This meant in most of the cases to use virtual tools or to finish the piloting in smaller groups [37]. In fact, in the case of pilot 2 in most of the cases should be delayed until month (after the authorization of the agency for extending the project). The schools commented that they must devote more time in preparing and conducting classes in online mode and later with social distance, so it was not possible to complete the pilots on time. Another change in the pilot is that due to COVID-19, the pilot 2 was concluded in the next academic year 2020/2021 instead of $2019 / 2020$, so some students were not in their institutions and therefore other students are involved [23].

\subsection{Sample of involved stakeholders}

Pilots have been divided in several phases, the first pilot include a diagnosis phase that involved a great number of students, the rest of the pilots are more reduced an involved less people. The environment where the pilots took place were five schools from different socioeconomic environments. They are described in Table 1 , that also includes a description of the students involved distinguishing between the diagnosis phase and pilots and the staff and researchers involved (labeled as Other) in each case. In the case of Portugal there are two schools,

It should be noted that in Pilot 2 and due to COVID-19 not always is possible to involve the same students that in the Pilot 1 , in some cases it is possible to include more students but in other cases they have left the school.

\subsection{Instruments employed for describing and assessing the pilots}

During one of the project meetings (Karlsruhe Transnational Meeting) the different kits and challenges gathered during the project were evaluated. Considering the project proposal each partner should address a challenge with a kit in the first piloting stage, but in the second challenges and kits should be exchanged.

Given this situation the partners decide [38]:

a. The granularity of the challenge to be addressed. During the academic course, given the restrictions of each institution learning plan, the better length for this experiment was that of a mini-challenge. The granularity should be the same or it would not be possible to compare the results in each institution. The possible levels of granularity have been discussed previously in [39].

b. Each partner of the piloting institution will address the minichallenge they proposed in the first staged (more information about the challenges is described in the next sections). 
Table 1: Stakeholders involved in the project pilots

\begin{tabular}{llllll}
\hline School Name & Diag.Phase & Pilot1 & Pilot2 & Teachers & Other \\
\hline I.E.S. Eras de Renueva (Spain) - I.E.R & 308 & 13 & 13 & 2 & 0 \\
Carl Benz School Karlsruhe (Germany) - CBSK & 13 & 17 & 17 & 1 & 6 \\
Agrupamento de Escolas Emídio Garcia (Portugal) - AEEG & 227 & 16 & 31 & 5 & 4 \\
Colégio Internato dos Carvalhos (Portugal) - CIC & 462 & 12 & 25 & 2 & 0 \\
University of Eastern Finland (Finland) - UEF & 32 & 10 & 5 & 2 & 0 \\
\hline
\end{tabular}

c. For the second piloting phase it is decided to exchange nanochallenges instead of mini challenges. Because they are easily addressable by the teams, considering the number of hours employed and the equipment and teachers' availability in each institution. ERAS nano challenges can be exchanged with KIT and AEEG, CIC nano-challenges can be exchanged with Finland and vice versa. AEEG nano-challenges can be exchanged with ERAS.

Regarding the instruments employed to assess the challenges the initial agreement between the partners was to establish some basic indicators and instruments to use [38]:

- As indicators the partnership agreed to use the time employed to complete the challenge, the number of persons involved in each team and the grade (that could later be compared with previous editions of the same subject).

- As evaluation instruments the partnership agreed to use the following [40]:

- The STEM Semantic Survey is a 25-item instrument that measures interest in science, technology engineering and mathematics as well as interest in STEM careers more generally. The Career Interest Questionnaire is a 12-item instrument that measures interest in careers in broad science areas [41]. It is applied during at the diagnosis phase and during the pilot with the experimental groups, in this case the people involved in the pilots will use the instrument before the first pilot and at the end of the experience. A link to the form is available here: https://forms.gle/vNQ8QCXkgtdTDGP57.

- Computational thinking test. It is an instrument initially aimed at Spanish students between 12 and 13 years old. It includes several to evaluate different areas related with computational thinking. The test has been properly validated and from the initial version of 40 items length it was depurated to 28 items [42]. It is applied at the end of the pilot 2 to see the computational thinking level of the students.

- Co-Measure Rubric. This instrument is defined for researchers and educators to use to assess student collaboration, at the individual level, when students are working in K-12 STEAM activities. It has been validated through several iterations and has been published [43]. During the project it is applied to assess the collaboration between team members in the pilot activities, but also during the exchanges when the students from the different schools have worked together. The STEM Semantic Survey will be used in the diagnosis phase [41]. Most of the partners need to ask for permissions and some of them to translate it and upload it to another platform different from Google (a google link to the form is available here: https://forms.gle/vNQ8QCXkgtdTDGP57..
Besides, this test will be employed in a pre- and post-test with the students implied in the challenges. In the post-test, also some questions regarding motivation. In addition, a computational thinking instrument to be used after the piloting that includes several CT dimensions. It is decided to use the if/else dimensions (from the conditionals section) and do/until dimension (from the loop section) because they are most related with robotics.

- Finally, teachers will also use a rubric to assess other competencies development.

\section{THE CHALLENGES ADDRESSED BY THE PARTNERS}

In this section we describe the challenges addressed in the project pilots by each of the schools attending to the templates defined in [39] to minimize the tables a facilitate readability we describe all the mini-challenges for pilot 1 and only some nano-challenges for pilot 2 .

\subsection{Pilot1 Mini-challenges}

In the following subsections we include the template for the minichallenges of each school and a brief description.

3.1.1 I.E.S. Eras de Renueva. The pilot carried out in I.E.S. Eras de Renueva in the context of RoboSTEAM project was carried out from October 2018 t0 January 2019. It involved 13 students 6 Female and 7 Male, with an age from 15 to 16, from three subjects: Control and Robotics, Technology and Coding.

3.1.2 Carl Benz School Pilot1. The pilot was held with trainees of the Carl-Benz-School Karlsruhe, a vocational school located in the city of Karlsruhe, for the professional fields of vehicle and metal engineering (commercial-technical field), in the framework of the German dual system of Vocational education and training. Specifically, it is developed with students of the course "Metal Engineering". The participants involved in the pilot were 17 trainees of metal technology/engineering as well as 6 university students of engineering pedagogy bachelor and master level to teach and support them as mentors.

3.1.3 Agrupamento de Escolas Emídio Garcia. This pilot was carried out in an Arts context, so the students were not so customed to technology and programming, to facilitate the development of the pilot it was carried out at the same time than the exchange C3 [44], that also with students of the IES Eras de Renueva. The challenge was carried out by 7 Art Portuguese students ( 5 boys and 2 girls), 4 Science and Technology students ( 3 boys and 1 girl) and 
8 Spanish students with an educational background related to technologies ( 4 girls and 4 boys); all of them are fifteen-year-olds. There were four groups which were made up of Portuguese and Spanish students: all of them with mixed abilities concerning STEAM related competences. Therefore, the groups were heterogeneous. The teachers monitored the ongoing challenge and assessed students' performance and competences acquisition based on Direct Observation. Teachers also considered the students' perception about the experiment to assess the Co-Measure Test. Moreover, each group appointed a spokesperson to give testimony of the experience.

3.1.4 University of Eastern Finland. The pilot 1, in University of Eastern Finland, was carried out in the Teacher Training School. Pilot was arranged as extra course for students interested in robotics and international student exchange. Interested students made applications to course and the group involved was chosen by teachers. Students were not required any knowledge of computational thinking or robotics. The participants in the pilots were 10, distributed in groups of 3 or 4 persons. Main goal of the challenge addressed was to design, construct and program a mobile robot using Hummingbird-kit with the aim of improving senior citizens life.

\subsection{Pilot2 Nano-challenges}

In this section we describe the different nano-challenge that one partners gather from the others and adapt to their context to carry out Pilot2.

3.2.1 I.E.S. Eras de Renueva. I.E.S. Eras de Renueva carried out the second pilot with the students of the first one. The students did not have previous knowledge about Robotics, although all of them acquired basic skills regarding electric circuits in Technology class ( $\left.1^{\circ} \mathrm{ESO}\right)$. The mini-challenge to be addressed was chosen from the use of heat sensors employed in the Wildfire challenge developed by AEEG during the pilot1. The challenge was adapted but the concepts to manage it are similar.

3.2.2 Carl Benz School. In this case in the framework of the minichallenge make it shine what the partners have done is to adapt the challenge defined by the I.E.S. Eras de Renueva of using a led to the context of the smart textile. It includes the teaching blocks 2, 3 and 4 defined for the original challenge. Teaching block 2 at developing a general basic understanding of computer science concepts and processes, including LED on and off task; this included above all an understanding of algorithms, i.e., if-then-relations. Theoretical knowledge was planned by playfully introducing students to the first principles of computer science by guiding a 'robot' (person) through the classroom with the help of simple control commands (right, straight ahead, turn $90^{\circ}$ to the left). The first basic ideas of loops were also discussed. In teaching blocks 3 and 4 the basic concepts of computer science already mentioned in block 2 were deepened and the students' projects were designed in groups and the 'smart textiles' were completed as far as possible. This implied the development of a circuit, the coding of the functionality of the work piece as well as a manual implementation by sewing and gluing.
3.2.3 Agrupamento de Escolas Emídio Garcia. This pilot2 was carried in COVID situation in the context of RoboSTEAM project from 19th November 2020 to 5th January 2021 at AEEG. It involves a challenge choose from the used by IES Eras during the first piloting phase. It was carried out by two classes. The class D is attending eleventh grade (secondary level) in Sciences and Technologies. It is made up of 21 students ( 17 boys and 4 girls), the average age is 16 years old. The Art class (11th E) is made up of ten students at the same age as the Sciences and Technologies student. Due to the restrictions related with this pandemic context, it was not possible to gather students from the two different classes. Being so, the Art students did the artwork and class D, after being given the art crafts.

The Art students created their art crafts individually, during Design A classes. Regarding Class D, it was split into 6 groups, yet, because they had to keep social distancing, these groups worked mainly on Monday free afternoons (2 groups at a time - each week); the final step of the challenge was achieved during Physics and Chemistry classes. All groups showed mixed abilities concerning not only STEAM related competences but also hands on tasks. Therefore, the groups were heterogeneous.

AEEG also created a Team for the project on the official school Learning Platform (Microsoft Teams) on which the communication between both teachers and students had a quite good flow. It was also used to store all documentation and evidence (mainly photos) of the ongoing project.

3.2.4 Colégio Internato dos Carvalhos. Pilot 2 was carried out at Colégio Internato dos Carvalhos, by students of the Electronics and Telecommunications course. Due to the pandemic situation, the time available for this challenge was too short and implemented with some restrictions. In this case they choose the challenge of University of Eastern Finland regarding Well-being of senior citizens defined for pilot1. In this case they adapt the challenge to the development of a dance robot that develops a choreography synchronized with the music in a limited space. The main objective is for the robot to perform a dance according to the music, that is, perform a choreography synchronized with the music in a limited space with the idea of amusing older people with health and mobility restrictions. The constraints for the robot were the following: 1) The chosen music had to have a time between 30 seconds to 1 minute; 2) The robot had to act on a 2-meter by 2-meter square; 3 ) The choreography should be representative of the music; 4) The robot's movements should be synchronized with the music; 5) All groups had the same time to develop the dance robot.

3.2.5 University of Eastern Finland. The pilot 2, in University of Eastern Finland, was carried out in the Teacher Training School but due, COVID-19 situation caused that part of the group finished their elementary school during the course so only 5 students carried out the course to end.

Main goal was to design, construct and program a mobile robot using Hummingbird-kit. They used challenge template as basis of the work described for pilot 1 , but they concentrated on challenges defined by CIC in pilot phase 1 . Students were able to use different materials for construction. After designing students programmed mobile robots. 
Table 2: Pilot indicators

\begin{tabular}{llll}
\hline Results for Pilot 1 & & & \\
\hline \hline School & Time & N-Nano challenges & Average \\
I.E.S Eras de Renueva & $20 \mathrm{~h}$ & 4 & 5,00 \\
Carl Benz School & $9 \mathrm{~h}$ & 3 & 3,00 \\
Agrupamento de Escolas Emídio Garcia & $35 \mathrm{~h}$ & 3 & 11,66 \\
Colégio Internato dos Carvalhos & $20 \mathrm{~h}$ & 3 & 6,66 \\
University of Eastern Finland & $30 \mathrm{~h}$ & 3 & 10,00 \\
Results for Pilot 2 & & & Average \\
School & Time & N-Nano challenges & 2,85 \\
I.E.S Eras de Renueva & $20 \mathrm{~h}$ & 7 & 3 \\
Carl Benz School & $6 \mathrm{~h}$ & 2 & 1,6 \\
Agrupamento de Escolas Emídio Garcia & $8 \mathrm{~h}$ & 5 & 20 \\
Colégio Internato dos Carvalhos & $20 \mathrm{~h}$ & 1 & 10 \\
University of Eastern Finland & 30 & 3 & \\
\hline
\end{tabular}

Table 3: Diagnosis phase results per schools

\begin{tabular}{llllll}
\hline Area & IER Grade & CBSK Grade & AEEG Grade & CIC Grade & UEF Grade \\
\hline Science & 4.45 & 4.52 & 4.69 & 4.60 & 3.49 \\
Math & 4.30 & - & 4.21 & 3.86 & 3.58 \\
Engineering & 4.37 & -29 & 3.84 & 4.26 & 3.40 \\
Arts & 3.99 & 4.75 & 4.00 & 3.83 & 3.65 \\
Technology & 4.47 & 4.23 & 4.51 & 4.80 & 4.09 \\
Career & 4.65 & & 4.77 & 4.62 & 3.72 \\
\hline
\end{tabular}

\section{RESULTS AND DISCUSSION}

Regarding the results there are different possible indicators and instruments for the assessment of the pilots, in this case we are going to focus on times to carry out the challenges, in an overview of the STEAM semantic survey results, in the products and in the teachers' perceptions.

There are different metrics, but an interesting one can be the time employed by the students to complete the challenges. In this case is difficult to quantify if a group has or not finished beyond the observation of the completion by the teacher but a general statement of the time devoted for the challenges can be seen in Table 2. In addition, we have included in this table the number of nanochallenges addressed and the average time per nano-challenge.

In the table it is possible to see that for the first pilot the time devoted per partner for the pilots goes from 3 hours required by the CBSK to 11.66 required by AEEG. It depends in many cases of the experience of the partners with the technology and the methodology and in the heterogeneity of the groups. In the case of the former they have been working with similar methodologies and all have the same background while in the latter the students come from different institutions and some of them (those with form ARTs) have different knowledge background. In the second pilot phase, there are to approaches some complete nano-challenges with their kits when they have developed the skills and therefore the time is reduced such as for AEEG or IER and some have done a more complex challenge such as CIC. In addition, it is interesting to consider the number of students involved and how they developed the work, that in the COVID-19 pandemic situation is not as in the first pilot. For instance, in some as CBSK and UEF they maintain the working methodology, but other such as AEEG distribute the work between teams to achieve a final goal, this means that the student should not address the whole challenge, but a part.

Other interesting issue is to know the landscape of students' perceptions about STEAM, this is achieved with the STEAM Semantic Survey and the results per partner are shown in Table 3

From the information gathered in this diagnosis phase we should comment [37]:

- In Spain school the values about the perception regarding the five areas is higher than the average value, with more relevant values in Science and Technology. Arts has he lower value and for the students a career with based on any of the areas is attractive.

- In Portugal there are two schools, one with a background more related to arts (AEEG) and other with a more related with technology (CIC). For both values are higher than the mean and are especially relevant for Science and Technology. However, it should be pointed out, that in AEEG the value for arts is higher than in the rest of the involved schools. For the careers as in Spain the tendency is a positive perception towards careers with the background on these areas.

- In Germany, as commented, the form was adapted so only Science, Engineering and Technology was studied and the results are like the ones obtained in Spain and Portugal, although with lower values for careers 

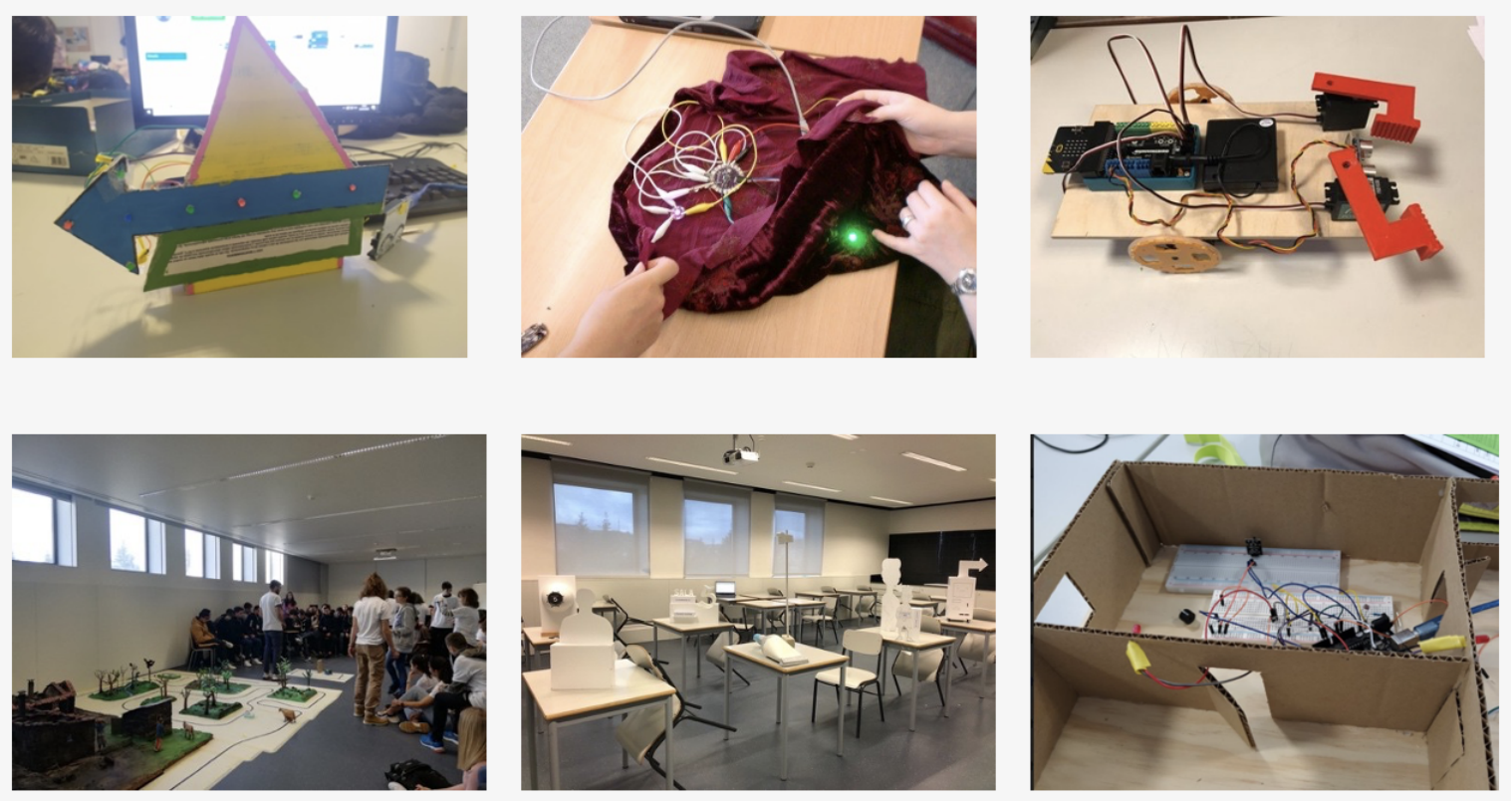

Figure 1: Results of pilots 1 and 2 in the different schools involved.

- In Finland the values are lower than in the other countries, especially in Engineering, which is probably because the educational model in this country. The most positive value is Technology in this case.

Finally, Figure 1 shows some of the results achieved during the first and second pilots and some videos can be found at: https: //drive.google.com/file/d/1PEfz4Ufh1dcYPRwUoXsFMxvJwMfw_ MHD/view?usp=sharing

Finally, it is interesting to gather some of the teachers' perception. In general perceptions were positive, the methodology was agile, and it allows the students to think not only in a task but in the general project. For some of the teachers (those from arts) the technology was a difficulty, but by mixing different students groups this problem was overcome and the results were quite satisfactory. In addition, some teachers argue about the difficulty of using the assessment instruments and in addition those required by their organization. In fact, partners such as UEF cannot apply some of the instruments and CBSK cannot consider all the parts of one of them.

\section{CONCLUSIONS}

Robotics in preuniversity education is used as the way to develop computational thinking skills and introduce to coding [45-50]. This work describes RoboSTEAM pilot phases, a key element of this Erasmus + Project to test both the methodology and validate the results obtained during the project. The results have shown that a Challenge Based Learning Approach using Robotics and Physical Devices can facilitate students' development of specific competences even with students from different fields. It has also shown the differences between different educational contexts, such as the flexibility to introduce new instrument or the way in which the students work together. Approaches such as RoboSTEAM facilitate overcoming these problems and make possible prepare the students to work together to solve a problem with a global point of view independently of the context in which it has been defined.

\section{ACKNOWLEDGMENTS}

This paper is supported by ROBOSTEAM Erasmus+ KA201 Project with reference 2018-1-ES01-KA201-050939.

\section{REFERENCES}

[1] F. J. García-Peñalvo and J. A. Mendes. 2018. Exploring the computational thinking effects in pre-university education. Computers in Human Behavior 80, 407-411. DOI:10.1016/j.chb.2017.12.005.

[2] Lev Manovich. 2013. Software takes command. A\&C Black.

[3] F. Llorens-Largo, F. J. García-Peñalvo, X. Molero Prieto, and E. Vendrell Vidal. 2017. La enseñanza de la informática, la programación y el pensamiento computacional en los estudios preuniversitarios. Education in the Knowledge Society 18, 2, 7-17. DOI:10.14201/eks2017182717.

[4] A. M. Pinto-Llorente, S. Casillas-Martín, M. Cabezas-González, and F. J. GarcíaPeñalvo. 2018. Building, coding and programming 3D models via a visual programming environment. Quality \& Quantity 52, 6, 2455-2468. DOI:10.1007/s11135017-0509-4.

[5] F. J. García-Peñalvo, F. Llorens Largo, X. Molero Prieto, and E. Vendrell Vidal. 2017. Educación en Informática sub 18 (EI<18). ReVisión 10, 2, 13-18.

[6] V Mccutcheon. 2010. Enquire Final Report.

[7] Ghislaine Gueudet. 2015. Internet Resources: Designing and Critiquing Materials for Scientific Inquiry. Encyclopedia of Science Education, 539-542.

[8] Ana M. Abril, Daniel Aguirre, Anna-Maria Aldorf, Szilárd András, Erzsébet Antal, Marta R. Ariza, Morten Blomhøj, Corine Den Boer, Patrick Bronner, Soňa Čeretková, Michiel Doorman, Jean-Luc Dorier, José Manuel Escobero, Josette Farrugia, Maria I. M. Febri, Fco. Javier García, Tünde Kontai, Henk Van Der Kooij, Ragnhild Lyngved, Katja Maaß, Janka Melušová, Ad Mooldijk, Nicholas G.Mousoulides, Eli Munkebye, Antonio Quesada, Zoltánné Sápi, Mikael Skånstrøm, Dana Strejčková, Malcolm Swan, and Csaba Tamási. 2013. Project PRIMAS - Inquiry Based Learning in Maths and Science Classes. University of Education, Freiburg, Germany. 
[9] Ts Ts Hristova. 2015. Innovative practices and technologies in educational projects of European Schoolnet and the project" Scientix. Bulgarian Chemical Communications 47, 505-508.

[10] Anthony Houghton, Adrian Oldknow, José Manuel Diego-Mantecón, Kristof Fenyvesi, Elizabeth Crilly, and Zsolt Lavicza. 2019. KIKS Creativity and Technology for All. Open Education Studies 1, 1, 198-208.

[11] Stella-Project. 2009. STELLA - Science Teaching in a Lifelong Learning Approach

[12] Veijo Meisalo, Jari Lavonen, and Kalle Juuti. 2006. Innovative approaches in school science-An analysis based on the GRID project data. Long-term Research in the Didactics of Mathematics and Science, 253.

[13] Stefan Haesen and Erwin Van De Put. 2018. STEAM Education in Europe: A Comparative Analysis Report. Eurosteam project.

[14] Laure Chémery. 2010. (YOSCIWEB) Young people and the images of science on websites Conseil général de l'Essonne.

[15] Stem-Alliance. 2016. STEM Education Factsheet - Executive Summary.

[16] Ingenious. 2014. Shaping the future of maths and science education.

[17] Raise. 2017. Raising Awarness and Interest in STEM Employment.

[18] A. García-Holgado, A. Camacho Díaz, and F. J. García-Peñalvo. 2019. Engaging women into STEM in Latin America: W-STEM project. In TEEM'19 Proceedings of the Seventh International Conference on Technological Ecosystems for Enhancing Multiculturality (Leon, Spain, October 16th-18th, 2019), M.Á. Conde-González, F.J Rodríguez-Sedano, C. Fernández-Llamas and F.J. García-Peñalvo Eds. ACM, New York, NY, USA, 232-239. DOI:10.1145/3362789.3362902.

[19] F. J. García-Peñalvo, A. Bello, A. Dominguez, and R. M. Romero Chacón. 2019 Gender Balance Actions, Policies and Strategies for STEM: Results from a World Café Conversation. Education in the Knowledge Society 20, 31-31 - 3115. DOI:10.14201/eks2019_20_a31.

[20] European-Comission. 2019. RoboSTEAM Project Description.

[21] Robosteam Consortium. 2021. Project Management Handbook. RoboSTEAM consortium.

[22] Robosteam Consortium. 2021. Pilot Phase 1-A3. RoboSTEAM consortium

[23] Robosteam Consortium. 2021. Pilot Phase 2 - A4. RoboSTEAM consortium

[24] H. Fardoun, C. S. González-González, C. A. Collazos, and M. Yousef. 2020. Estudio exploratorio en Iberoamérica sobre procesos de enseñanza-aprendizaje y propuesta de evaluación en tiempos de pandemia. Education in the Knowledge Society 21. DOI:10.14201/eks.23537.

[26] F. J. García-Peñalvo, A. Corell, V. Abella-García, and M. Grande-De-Prado. 2020 Online Assessment in Higher Education in the Time of COVID-19. Education in the Knowledge Society 21. DOI:10.14201/eks.23013.

[26] J. Cabero-Almenara and C. Llorente-Cejudo. 2020. Covid-19: radical transformation of digitization in university institutions. Campus Virtuales 9, 2, 25-34.

[27] Sir John Daniel. 2020. Education and the COVID-19 pandemic. PROSPECTS 49 , 91-96. DOI:10.1007/s11125-020-09464-3

[28] Â. Fidalgo-Blanco, M. L. Sein-Echaluce, and F. J. García-Peñalvo. 2020. Hybrid Flipped Classroom: adaptation to the COVID situation. In Proceedings TEEM'20. Eighth International Conference on Technological Ecosystems for Enhancing Multiculturality (Salamanca, Spain, October 21st - 23rd, 2020), F.J. García-Peñalvo Ed. ACM, New York, NY, USA. DOI:10.1145/3434780.3436691.

[29] F. J. García-Peñalvo and A. Corell. 2020. La COVID-19: ¿enzima de la transformación digital de la docencia o reflejo de una crisis metodológica y competencial en la educación superior? Campus Virtuales 9, 2, 83-98.

[30] F. J. García-Peñalvo, A. Corell, V. Abella-García, and M. Grande-De-Prado. 2021 Recommendations for Mandatory Online Assessment in Higher Education During the COVID-19 Pandemic. In Radical Solutions for Education in a Crisis Context COVID-19 as an Opportunity for Global Learning, D. Burgos, A. Tlili and A. Tabacco Eds. Springer Nature, Singapore, Singapore, 85-98. DOI:http://dx.doi. org/10.1007/978-981-15-7869-4_6.

[31] F. J. García-Peñalvo, A. Corell, R. Rivero-Ortega, M. J. Rodríguez-Conde, and N. Rodríguez-García. 2021. Impact of the COVID-19 on Higher Education: An Experience-Based Approach. In Information Technology Trends for a Global and Interdisciplinary Research Community, F.J. García-Peñalvo Ed. IGI Global, Hershey, PA, USA, 1-18. DOI:http://dx.doi.org/10.4018/978-1-7998-4156-2.ch001.

[32] Maria Nicola, Zaid Alsafi, Catrin Sohrabi, Ahmed Kerwan, Ahmed Al-Jabir, Christos Iosifidis, Maliha Agha, and Riaz Agha. 2020. The socio-economic implications of the coronavirus pandemic (COVID-19): A review. International fournal of Surgery 78, 185-193. DOI:http://dx.doi.org/10.1016/j.ijsu.2020.04.018.

[33] Wim Van Lancker and Zachary Parolin. 2020. COVID-19, school closures, and child poverty: a social crisis in the making. The Lancet Public Health 5, 5, e243-e244
DOI.http://dx.doi.org/10.1016/S2468-2667(20)30084-0.

[34] Russell M. Viner, Simon J. Russell, Helen Croker, Jessica Packer, Joseph Ward, Claire Stansfield, Oliver Mytton, Chris Bonell, and Robert Booy. 2020. School closure and management practices during coronavirus outbreaks including COVID19: a rapid systematic review. The Lancet Child \& Adolescent Health 4, 5, 397-404. DOI:http://dx.doi.org/10.1016/S2352-4642(20)30095-X.

[35] R. Gil-Fernández, A. León-Gómez, and D. Calderón-Garrido. 2021. Influence of COVID on the Educational Use of Social Media by Students of Teaching Degrees. Education in the Knowledge Society 22. DOI:http://dx.doi.org/10.14201/eks.23623.

[36] A. Corell and F. J. García-Peñalvo. 2021. COVID-19: La encerrona que transformó las universidades en virtuales. Gaceta Cultural, 91, 23-26.

[37] M. Á. Conde, F. J. Rodríguez-Sedano, C. Ferández-Llamas, M. J. Ramos, J. Alves, S. Celis-Tena, J. Gonçalves, J. Lima, D. Reimann, I. Jormanainen, and F. J. García Peñalvo. 2020. Adaption of RoboSTEAM Project to the Pandemic Situation. In Proceedings TEEM'20. Eighth International Conference on Technological Ecosystems for Enhancing Multiculturality (Salamanca, Spain, October 21st - 23rd, 2020), F.J. García-Peñalvo Ed. ACM, New York, NY, USA. DOI:10.1145/3434780.3436620.

[38] Robosteam Consortium. 2019. Application of the kits - O2.A5.

[39] M. Á. Conde, C. Fernández-Llamas, J. F. Ribeiro Alves, M. J. Ramos, S. Celis Tena, J. Gonçalves, J. Lima, D. Reimann, I. Jormanainen, and F. J. García-Peñalvo. 2019. RoboSTEAM - A Challenge Based Learning Approach for integrating STEAM and develop Computational Thinking. In TEEM'19 Proceedings of the Seventh International Conference on Technological Ecosystems for Enhancing Multiculturality (Leon, Spain, October 16th-18th, 2019), M.Á. Conde-González, F.J. Rodríguez-Sedano, C. Fernández-Llamas and F.J. García-Peñalvo Eds. ACM, New York, NY, USA, 24-30. DOI:10.1145/3362789.3362893

[40] Robosteam Consortium. 2021. Evaluation of the experiences - O2.A6. RoboSTEAM consortium.

[41] Tandra Tyler-Wood, Gerald Knezek, and Rhonda Christensen. 2010. Instruments for assessing interest in STEM content and careers. Fournal of Technology and Teacher Education 18, 2, 345-368.

[42] Marcos Román-Gonzalez, Juan Carlos Pérez-González, and Carmen JiménezFernández. 2015. Test de Pensamiento Computacional: diseño y psicometría general. In III congreso internacional sobre aprendizaje, innovación y competitividad (CINAIC 2015), 1-6.

[43] Danielle Herro, Cassie Quigley, Jessica Andrews, and Girlie Delacruz. 2017. CoMeasure: developing an assessment for student collaboration in STEAM activities. International Journal of STEM Education 4, 1 (2017/11/15), 26. DOI:http://dx.doi. org/10.1186/s40594-017-0094-z.

[44] M. Á. Conde, F. J. Rodríguez-Sedano, C. Fernández-Llamas, M. Jesus, M. J. Ramos, S. Celis-Tena, J. Gonçalves, I. Jormanainen, and F. J. García-Peñalvo. 2020. Exchanging Challenge Based Learning Experiences in the Context of RoboSTEAM Erasmus+ Project. In Learning and Collaboration Technologies. Design, Experiences. 7th International Conference, LCT 2020, Held as Part of the 22nd HCI International Conference, HCII 2020, Copenhagen, Denmark, July 19-24, 2020, Proceedings, Part I, P. Zaphiris and A. Ioannou Eds. Springer Nature, Cham, Switzerland, 442-455. DOI:10.1007/978-3-030-50513-4_33.

[45] G. Chiazzese, G. Fulantelli, V. Pipitone, and D. Taibi. 2018. Engaging Primary School Children in Computational Thinking: Designing and Developing Videogames. Education in the Knowledge Society 19, 2, 63-81. DOI:10.14201/eks20181926381.

[46] C. S. González-González. 2019. State of the art in the teaching of computational thinking and programming in childhood education. Education in the Knowledge Society 20. DOI:10.14201/eks2019_20_a17.

[47] J. F. Álvarez-Herrero. 2020. Computational Thinking in Early Childhood Education, beyond Floor Robots. Education in the Knowledge Society 21. DOI:10.14201/eks.22366.

[48] J. González Martínez, M. Estebanell Minguell, and M. Peracaula Bosch. 2018. ¿Robots o programación? El concepto de Pensamiento Computacional y los futuros maestros. Education in the Knowledge Society 19, 2, 29-45. DOI:10.14201/eks20181922945.

[49] Cristian Ferrada-Ferrada, Javier Carrillo-Rosúa, Danilo Díaz-Levicoy, and Francisco Silva-Díaz. 2020. Robotics from STEM areas in Primary School: a Systematic Review. Education in the Knowledge Society 21. DOI:10.14201/eks.22036.

[50] M. Á. Conde, F. J. Rodríguez-Sedano, C. Fernández-Llamas, J. Gonçalves, J. Lima, and F. J. García-Peñalvo. 2021. Fostering STEAM through Challenge Based Learning, Robotics and Physical Devices: A systematic mapping literature review. Computer Application in Engineering Education 29, 46-65. DOI:10.1002/cae.22354. 